Article

\title{
The Public Value of Reducing the Incidence of Oil Spill Accidents in Korean Rivers
}

\author{
Hye-Jeong Lee, Hyo-Jin Kim and Seung-Hoon Yoo * (i) \\ Department of Energy Policy, Graduate School of Energy \& Environment, Seoul National University of Science \\ \& Technology, 232 Gongreung-Ro, Nowon-Gu, Seoul 01811, Korea; hjeonglee@seoultech.ac.kr (H.-J.L.); \\ hjinkim@seoultech.ac.kr (H.-J.K.) \\ * Correspondence: shyoo@seoultech.ac.kr; Tel.: +82-2-970-6802
}

Received: 2 March 2018; Accepted: 11 April 2018; Published: 13 April 2018

\begin{abstract}
Oil spill accidents involving cars or boats for transport in rivers can contaminate drinking water sources. During the past ten years, an annual average of forty-six cases of oil spill accidents have occurred in Korean rivers. Because of this, the Korean government is seeking to reduce the incidence of oil spill accidents in rivers by half. This article aims to evaluate the public value of the reduction. Household willingness to pay (WTP) for the reduction was investigated, applying the contingent valuation approach. A survey of 1000 households was carried out in Korea. The data on the WTP were gathered using a dichotomous choice question and analyzed employing the spike model. The mean WTP estimate is obtained as KRW 6188 (USD 5.28) per household per annum, which is statistically meaningful. The total public value expanded to the population amounts to KRW 120.8 billion (USD 103.0 million) per year. The information can be utilized in policy-making and decision-making about the reduction of the incidence of oil spill accidents in rivers by half.
\end{abstract}

Keywords: oil spill accident; water pollution; willingness to pay; public value; contingent valuation

\section{Introduction}

Oil spill accidents in rivers can cause an immediate and devastating effect on wildlife and the ecosystem, and can be harmful to the health of the residents in the impacted area, since they can pollute drinking water sources. Oil can contain more than one hundred contaminants, all of which are hazardous and toxic substances [1]. Therefore, if humans and animals are exposed to these substances, they may cause various diseases, such as cancer, genotoxicity, fetal growth defects, cardiovascular disease, DNA adducts in fish, bioaccumulation, and so on [1-5].

Our country has land characteristics such as the enlargement of industrial facilities, obsolescence, an increase in multi-use facilities, and concentrated living space. Therefore, we anticipate increasing oil spills and human and social damage due to crowding. According to recent statistics, during the past decade, an annual average of 46 oil spill accidents have occurred in Korean rivers [6]. For instance, there are many rivers containing various construction works in Korea, and dredgers frequently cause oil spill accidents on these construction sites. In addition, an oil tanker carrying diesel crashed into Chuncheon Lake, resulting in the leakage of $2000 \mathrm{~L}$ of oil. As the number of accidents increases, the Korean Government's budget to restore the damage also increases every year. Therefore, the Government plans to implement various national plans to procure systematic incident response capability by implementing an integrated accident response system, establishing an accident prevention response system, and securing a relief system for environmental pollution [7].

Oil spill accidents mostly occur in marine areas; thus, research on marine accidents and safety management is active in accordance with the increasing maritime usage [8-12]. Moreover, maritime accidents—undesired abnormal events involving a ship that often result in loss of life or major injury 
to any person on board and in various types of property damage-have been a major issue in the international maritime community since shipping began [13]. However, research and policy on oil spill accidents in rivers are insufficient, despite the steady increase in oil spill accidents in rivers used for drinking water and agricultural water.

Therefore, the Korean Government is considering a plan to reduce the incidence of oil spill accidents in rivers by $50 \%$. Government officials are requesting information about the value that the enforcement of the reduction plan produces to the public, which is of great help to obtain some implications concerning whether the reduction should be performed or not. For this purpose, this study strives to derive household willingness to pay (WTP) for the reduction. The rest of this article consists of five sections. Section 2 presents a short review of some former studies. Section 3 describes the methodology that this article adopts. Section 4 explains the economic model for dealing with the WTP data. Section 5 provides the results and a discussion thereof. Section 6 provides conclusions.

\section{A Short Review of Some Former Studies}

The task of dealing with the measurement of the public value of reducing the incidence of oil spill accidents or the damage cost caused by oil spill accidents is the responsibility of researchers [14-18]. There have been many studies on this measurement, as reported in Table 1. From the literature review, it is found that stated preference (SP) methods have usually been applied to carry out such tasks. The SP methods usually ask people to state their WTP for consuming the goods or services concerned. Two representative approaches belonging to SP methods are the contingent valuation (CV) approach (e.g., [19-22]) and choice experiment (CE) approach (e.g., [23,24]). The former elicits the WTP response directly. However, the latter derives the WTP responses indirectly.

Table 1. A summary of the observations from some former studies.

\begin{tabular}{|c|c|c|c|}
\hline Countries & Sources & Methodologies $^{\text {a }}$ & Yearly Household Willingness to Pay \\
\hline United States & Carson et al. [19] & $\mathrm{CV}$ & $\begin{array}{l}\text { For preventing an Exxon Valdez-type oil } \\
\text { spill: USD } 48\end{array}$ \\
\hline Belgium & van Biervliet et al. [20] & $\mathrm{CV}$ & $\begin{array}{l}\text { For preventing hypothetical oil spill } \\
\text { scenarios: EUR } 12 \text { to } 59\end{array}$ \\
\hline Finland & Ahtiainen [21] & $\mathrm{CV}$ & $\begin{array}{l}\text { For building up the oil spill response } \\
\text { capacity in the Gulf of Finland: EUR } 73.57\end{array}$ \\
\hline Brazil & Casey et al. [23] & CE & $\begin{array}{l}\text { For avoiding the risk of oil spills by } \\
\text { reducing the chance of oil spills: USD } 472 \\
\text { For avoiding the risk of oil spills by } \\
\text { reducing the size of oil spills: USD } 214 \\
\text { For avoiding the risk of oil spills by } \\
\text { compensation for health problems caused } \\
\text { by oil spills: USD } 260 \\
\text { For avoiding the risk of oil spills by } \\
\text { compensation for education problems } \\
\text { caused by oil spill: USD } 129\end{array}$ \\
\hline Germany & Liu et al. [24] & CE & $\begin{array}{l}\text { For hindering coastal resources from } \\
\text { being polluted by oil spills in the Wadden } \\
\text { Sea: EUR } 29.1\end{array}$ \\
\hline Spain & Loureiro et al. [22] & $\mathrm{CV}$ & $\begin{array}{l}\text { For averting a future oil spill in Spain: } \\
\text { EUR } 40.51\end{array}$ \\
\hline
\end{tabular}

Notes: ${ }^{\mathrm{C}} \mathrm{CV}$ and CE imply contingent valuation and choice experiment, respectively.

For example, Carson et al. [19] estimated the non-use value for damages from the 1989 Exxon Valdez oil spill in Alaska using the CV technique. The median WTP for preventing another Exxon Valdez-type oil spill was USD 48 per household per year. van Biervliet et al. [20] examined the WTP for preventing hypothetical oil spill scenario along the Belgian Coast. The annual WTP per household 
is worth EUR 12 to 59, depending on some conditions. Ahtiainen [21] applied a CV technique to elicit the public WTP for improving the capacity of oil spill response using the specific case of the Gulf of Finland. The mean WTP estimate was calculated as EUR 73.57 per household per year. Loureiro et al. [22] conducted a CV survey after a Prestige oil spill in Spain. The mean WTP estimate for preventing a future oil spill was EUR 40.51 per household per year.

Casey et al. [23] employed the choice experiment method to assess the public WTP for avoiding the environmental risks caused by oil transport in the Amazon River. The marginal WTP estimates from reducing the chance of oil spills, reducing the size of oil spills, compensation for the education problems caused by oil spills, and compensation for the health problems caused by oil spills were USD 472, 214, 260, and 129 per household per year, respectively. Liu et al. [24] employed a CE and analyzed household WTP for preventing coastal resources from being polluted by the oil spill in the Wadden Sea. The attributes utilized as indicators of oil spill management were coastal waters, beaches, birds, and the oil collection ratio. The average household WTP for the attributes was computed as EUR 29.1 per annum in the study.

\section{Methodology}

\subsection{Object to Be Investigatied}

Overall the number of oil spill accidents in rivers has been increasing every year. The detailed status of the number of oil spill accidents in rivers is shown in Table 2. Therefore, the object of investigation in our study is the governmental plan to reduce the incidence of oil spill accidents in rivers by half. The expected effects from carrying out the reduction plan are that the quality of the water source will be preserved well, and the residents and ecosystem in the impacted area will be able to curtail the damage from water pollution. These were conveyed and explained to the respondents through the use of newspaper articles, color pictures, and well-made presentation materials during the CV survey.

Table 2. Apparent trend of the frequency of water pollution accidents.

\begin{tabular}{cccccc}
\hline Year & Oil Spill & Chemical Substance Spill & Fish Mortality & Others & Totals \\
\hline 2005 & 30 & 7 & 11 & 11 & 59 \\
2006 & 16 & 8 & 7 & 21 & 52 \\
2007 & 18 & 8 & 10 & 14 & 50 \\
2008 & 20 & 6 & 10 & 17 & 53 \\
2009 & 23 & 5 & 19 & 13 & 60 \\
2010 & 46 & 6 & 17 & 17 & 86 \\
2011 & 38 & 6 & 11 & 13 & 68 \\
2012 & 42 & 3 & 14 & 24 & 83 \\
2013 & 69 & 24 & 24 & 40 & 157 \\
2014 & 89 & 16 & 70 & 37 & 212 \\
2015 & 58 & 7 & 49 & 19 & 133 \\
2016 & 55 & 8 & 38 & 15 & 116 \\
Totals & 504 & 104 & 280 & 241 & 1129 \\
\hline \multicolumn{5}{c}{ Source: Korea Environment Corporation $[6]}$. \\
\end{tabular}

\subsection{Method: CV Approach}

As addressed above, this article aims to look into people's WTP for reducing the incidence of oil spill accidents in Korean rivers by half. This study will employ the CV approach instead of the CE approach because the first [25] is much simpler to apply than the second, and the attributes required in using the CE approach are not well-defined in this study. Our research can be compared with previous studies in four respects. First, the studies that measured people's WTP for reducing the incidence of oil spill accidents in Korean rivers by half remain scarce. Most of the related studies have tackled oil spill accidents on the coast or the deep water horizon. This is the case for Korea [26-29]. 
Second, our application of the CV technique coincides with the practice adopted in the former studies dealing with this kind of research topic. Moreover, the CV technique is based on microeconomics and thus theoretically sound [30]. Since the findings from this article may be used in policy-making and analysis, it is crucial to use reasonable and sound methodology. The CV technique is not only practically useful, but also theoretically robust.

Third, we tried to follow several guidelines recommended for applying the CV approach in the literature. They include the use of a dichotomous choice (DC) question, a minimum sample size of 1,000 , the adoption of a tax rather than a donation, a fund or a usage fee as a payment vehicle, the employment of annual payment rather than one-shot payment or monthly payment as a payment method, the announcement of the possible presence of substitutes for the goods to be investigated in the CV survey, and so on. More details will be presented in the next subsections.

Fourth, when eliciting the WTP responses, this study paid more attention to not only mitigating the response bias but also augmenting the statistical efficiency. This article employs a single-bounded (SB) DC method given in Hanemann [31], which can produce less response bias than the double-bounded (DB) DC method. Furthermore, the spike model proposed by Kriström [32] is combined with the SB DC method in order to model the WTP data with zero observations. Figure 1 shows the procedure for applying the CV approach.
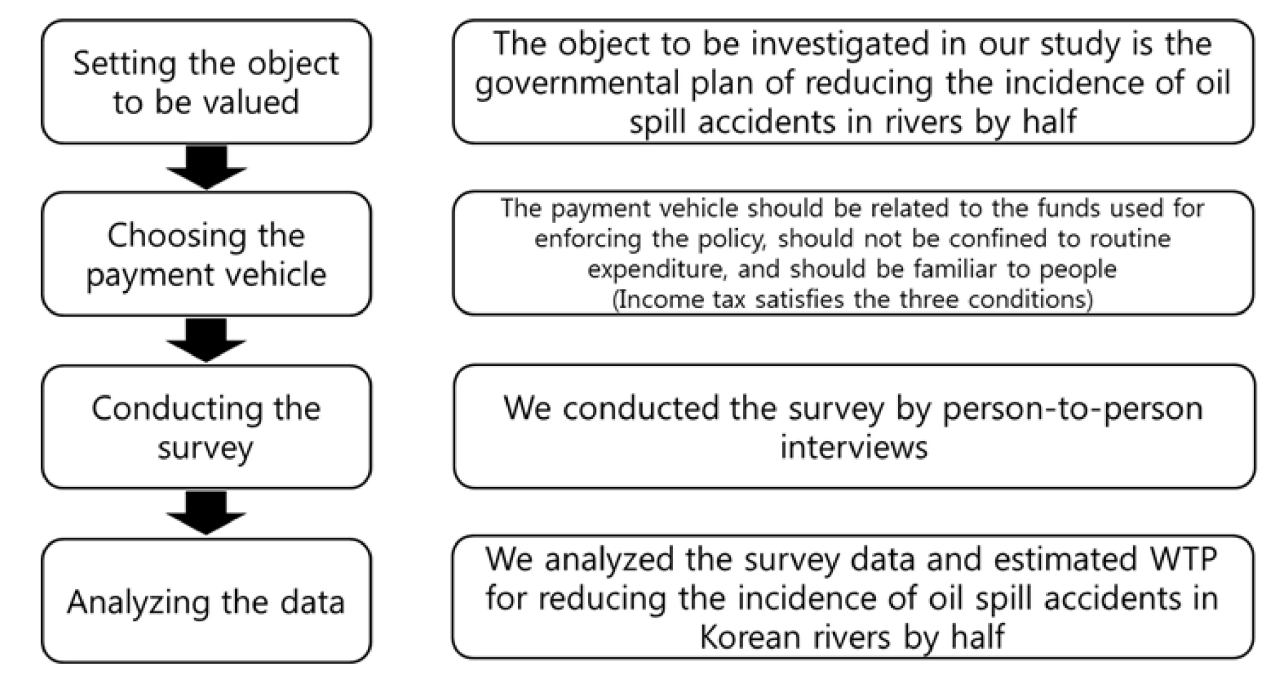

Figure 1. Procedure for applying the contingent valuation (CV) approach in this study.

\subsection{Sample and Survey Instrument}

In consideration of the research budget, we decided to set the sample size at 1000 . The 1000 respondents were allocated into each province proportionally to the total number of households in each province given in Statistics Korea [33]. In this regard, our sampling method was stratified random sampling. Each province was a stratum. Within each province, the allocated number of households was randomly selected. The entire process of sampling and carrying out the survey was administered by a professional survey firm during July 2016. The firm sought to ensure that the sample characteristics represented the population characteristics well. An experienced specialist at the firm ran the whole process.

A pretest using a focus group of thirty persons was implemented with an earlier version of the survey instrument to examine whether it is understandable and clear enough for the interviewees to finish filling in the survey questionnaire. The outcomes of the in-depth interviews with the focus group were utilized to make the questionnaires fully corrected for use in the main survey. Its final version is made up of four parts. The first part presents the background and objective of the survey. The second part includes several questions deriving the interviewees' opinions and judgment regarding the plan 
of reducing the incidence of oil spill accidents in rivers by half. The third part deals with questions about the WTP for the reduction plan. Some questions about respondents' characteristics are given in the final part.

\subsection{Elicitation of WTP}

As explained above, this article adopted a SB DC question to gather the WTP responses. The DC question was originally recommended for use in the field CV survey by a number of studies. The main reason for the recommendation is that it can reduce the respondents' burden of answering the WTP question and derive an incentive-compatible response from interviewees [31]. The DC question is quite simple. The only work for a respondent to do is to state "yes" or "no" to a given bid amount. The respondent will report "yes" if her/his WTP for the reduction plan is more than or equal to an offered bid and "no" otherwise. On the other hand, an open-ended question of directly asking the WTP value is not preferred to the DC question in the literature because the former can induce a number of protest WTP responses [30,34,35]. Most of the CV studies adopting the DC question have applied the SB or DB DC formats. The SB DC format has the benefit of alleviating any response bias arising from the use of the DB DC format.

One complication involved in applying the CV is that it puts people in a hypothetical situation and thus the respondents can have difficulties in stating their true WTP. An appropriate payment can help the respondents confronted with the hypothetical situation report their WTP, making them feel as if they were in the real world. Some examples of the payment vehicle include a tax such as income tax or property tax, a donation, a fund, a usage fee, and so on. The payment vehicle should be related to the funds used for enforcing the policy, should not be confined to routine expenditure, and should be familiar to people. We decided that the payment vehicle meeting the three conditions is income tax. Thus, the WTP question presented to the respondents was "Would your household accept an amount of increase in annual income tax to reduce the incidence of oil spill accidents in Korean rivers by half?"

\section{WTP Model}

\subsection{SB DC Model}

Hanemann [31] proposed an approach to model the SB DC CV data. $A_{j}$ is defined as a bid presented to respondent $j$. Before implementing the field CV survey, we need to determine a set of bids. A bid is randomly selected of the several bids and presented to each interviewee. The interviewees are asked to say "yes" or "no" to the payment of $A_{j}$, and an additional question is not required. Let $Y_{j}$ be the interviewee's WTP. Two responses, "yes" $\left(Y_{j} \geq A_{j}\right)$ and "no" $\left(Y_{j}<A_{j}\right)$, can emerge from the situation where $A_{j}$ is offered. Therefore, let $I_{j}^{Y}$ and $I_{j}^{N}$ be binary variables which correspond to the two kinds of responses. For instance, $I_{j}^{Y}$ is one if the $j$ th interviewee reports "yes", and zero otherwise.

\subsection{Combination of SB DC Question and Spike Model}

An additional question, "Would your household agree to pay anything?", was given to the respondents who stated "no" to the bid. Her/his WTP is less than the bid and more than zero if the answer is "yes." Her/his WTP is zero if the answer is "no." One more binary variable, $I_{j}^{T Y}$, is defined as one if the answer is "yes" and zero otherwise. Thus, there are three outcomes:

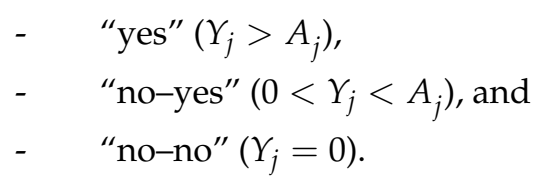

As will be explained below, out of the 1000 respondents, 480 said they had no intention of paying anything. Thus, the spike model can be usefully employed to deal with the WTP data. Considering 
that the most frequently used distribution in analyzing DC CV data is logistic distribution, we specify the WTP distribution function, $F_{Y}(\cdot)$, as:

$$
F_{Y}\left(A ; \gamma_{0}, \gamma_{1}\right)= \begin{cases}{\left[1+\exp \left(\gamma_{0}-\gamma_{1} A\right)\right]^{-1}} & \text { if } A>0 \\ {\left[1+\exp \left(\gamma_{0}\right)\right]^{-1}} & \text { if } A=0 \\ 0 & \text { if } A<0\end{cases}
$$

where $\gamma_{0}$ and $\gamma_{1}$ are the parameters of $F_{Y}(\cdot)$.

The log-likelihood function for the model is:

$$
\begin{aligned}
\ln L= & \sum_{j=1}^{S}\left\{I_{j}^{Y} \ln \left[1-F_{Y}\left(A_{j} ; \gamma_{0}, \gamma_{1}\right)\right]\right. \\
& +I_{j}^{T Y} \cdot I_{j}^{N} \ln \left[F_{Y}\left(A_{j} ; \gamma_{0}, \gamma_{1}\right)-F_{Y}\left(0 ; \gamma_{0}, \gamma_{1}\right)\right], \\
& \left.+\left(1-I_{j}^{T Y}\right) \cdot I_{j}^{N} \cdot \ln F_{Y}\left(0 ; \gamma_{0}, \gamma_{1}\right)\right\}
\end{aligned}
$$

where $S$ is the sample size.

We can get the estimates for $\gamma_{0}$ and $\gamma_{1}$ by finding the values for $\gamma_{0}$ and $\gamma_{1}$ maximizing Equation (2), that is, using the maximum likelihood estimation method. When using Equation (1) and the estimates for $\gamma_{0}$ and $\gamma_{1}$, the average WTP can be obtained as:

$$
E(Y)=\int_{0}^{\infty}\left[1-F_{Y}\left(A ; \gamma_{0}, \gamma_{1}\right)\right] d A-\int_{-\infty}^{0} F_{Y}\left(A ; \gamma_{0}, \gamma_{1}\right) d A=\left(1 / \gamma_{1}\right) \ln \left[1+\exp \left(\gamma_{0}\right)\right] .
$$

\section{Results and Discussion}

\subsection{Data}

The list of sets of bids used in the CV survey is KRW 1000, 2000, 3000, 5000, 7000, 10,000, and 15,000. USD 1.0 was equal to KRW 1173 when the survey was conducted. The list of bids was determined through the focus group interview of thirty individuals as follows: first, we asked the WTP for the reduction and obtained a set of WTP values; second, we deleted zero WTP values and then sorted the remaining positive WTP values to look into empirical distribution; third, some bids were selected from the distribution. One of seven bids was randomly offered to the interviewees. Finally, 1000 useable observations were obtained from the CV survey. Table 3 reports a summary of

\begin{tabular}{|c|c|c|c|c|}
\hline \multirow{2}{*}{ Bid Amount ${ }^{a}$} & \multicolumn{3}{|c|}{ Number of Responses (\%) $b$} & \multirow{2}{*}{ Sample Size } \\
\hline & "Yes" & “No-Yes" & “No-No" & \\
\hline 1000 & $85(59.4 \%)$ & $14(9.8 \%)$ & $44(30.8 \%)$ & $143(100.0 \%)$ \\
\hline 2000 & $65(45.5 \%)$ & $22(15.4 \%)$ & $56(39.2 \%)$ & $143(100.0 \%)$ \\
\hline 3000 & $62(43.4 \%)$ & $18(12.6 \%)$ & $63(44.1 \%)$ & $143(100.0 \%)$ \\
\hline 5000 & $46(32.2 \%)$ & $27(18.9 \%)$ & $70(49.0 \%)$ & $143(100.0 \%)$ \\
\hline 7000 & $35(24.5 \%)$ & 31 (21.7\%) & 77 (53.8\%) & $143(100.0 \%)$ \\
\hline 10,000 & $42(29.4 \%)$ & 21 (14.7\%) & $80(55.9 \%)$ & $143(100.0 \%)$ \\
\hline 15,000 & $28(19.7 \%)$ & $24(16.9 \%)$ & $90(63.4 \%)$ & $142(100.0 \%)$ \\
\hline Totals & $363(36.3 \%)$ & $157(15.7 \%)$ & $480(48.0 \%)$ & $1000(100.0 \%)$ \\
\hline
\end{tabular}
the interviewees' responses to each bid. Overall, 363, 157, and 480 interviewees gave "yes", "no-yes", and "no-no" responses, respectively. Out of the 1000 respondents, 480 said they had no intention of paying anything ("no-no" responses).

Table 3. Summary of the interviewees' responses.

Notes: ${ }^{a}$ The unit is the Korean Won (USD 1.0 = KRW 1173 at the time of the survey). ${ }^{\mathrm{b}}$ The percentage of sample size is given in parentheses beside the number of responses. 


\subsection{Estimation Results of the Model}

Table 4 presents the estimation results of the model. The estimate for $\gamma_{1}$ was statistically significant. In particular, the negative sign of the estimate for $\gamma_{1}$ means that a higher bid amount induced a lower probability of saying "yes" to a given bid. From Equation (1), the spike is derived as $\left[1+\exp \left(\gamma_{0}\right)\right]^{-1}$. The estimate for the spike was calculated as 0.4871 and was statistically significant. Because the spike implies the possibility of the interviewee having zero WTP, the estimated spike should not be significantly different from the sample ratio of zero WTP (48.0\%). This was the case with our study.

Table 4. Estimation results of the model.

\begin{tabular}{|c|c|}
\hline Variables & Coefficient Estimates $^{d}$ \\
\hline Constant & $0.0514(0.80)$ \\
\hline Bid amount ${ }^{a}$ & $-0.1162(-14.70)^{\#}$ \\
\hline Spike & $0.4871(30.48)^{\#}$ \\
\hline Yearly mean WTP per household & KRW 6188 (USD 5.28) \\
\hline$t$-value & $14.54^{\#}$ \\
\hline $95 \%$ confidence interval $^{b}$ & KRW 5477 to 7115 (USD 4.67 to 6.07 ) \\
\hline Yearly median WTP per household & KRW 443 (USD 0.38) \\
\hline$t$-value & 0.82 \\
\hline $95 \%$ confidence interval ${ }^{b}$ & KRW -622 to 1480 (USD -0.53 to 1.26$)$ \\
\hline Number of observations & 1000 \\
\hline Log-likelihood & -1019.64 \\
\hline Wald statistic ( $p$-value $)^{\mathrm{c}}$ & $211.54(0.000)$ \\
\hline
\end{tabular}

Notes: a The unit is KRW 1000, and the exchange rate was USD $1.0=$ KRW 1173 at the time of the survey. ${ }^{\mathrm{b}}$ It is calculated using the parametric bootstrapping method given in Krinsky and Robb [36]. ${ }^{\mathrm{c}}$ It is calculated under the null hypothesis of all parameters being jointly zero. ${ }^{\mathrm{d}}$ The values reported in parentheses beside the coefficient estimates are $t$-values. "\# implies statistical meaningfulness at the $1 \%$ level. WTP: willingness to pay.

Table 4 also provides an estimate of average WTP calculated using Equation (3). The yearly average WTP had the value of KRW 6188 (USD 5.28) per household and was statistically meaningful. It is desirable to calculate its confidence interval to account for the uncertainties associated with computing the point estimate for the mean WTP. The 95\% confidence interval computed adopting the parametric bootstrapping method presented in Krinsky and Robb [36] was KRW 5418 to 7125 (USD 4.62 to 6.07). In addition, the yearly median WTP had the value of KRW 443 (USD 0.38) per household. The $t$-value computed under the null hypothesis that the coefficient is zero was 0.82 . Thus, the null hypothesis cannot be rejected, and the median WTP estimate was not statistically significant.

\subsection{Reflection of Covariates}

Covariates are the factors that can have an effect on the probability of saying "yes" to a provided bid. Generally, the interviewees' characteristics were used as covariates. We considered four variables: income, householder, education level, and gender. Table 5 explains the variables.

Table 5. Description of the variables used for covariates.

\begin{tabular}{clcc}
\hline Variables & \multicolumn{1}{c}{ Definitions } & Mean & Standard Deviation \\
\hline Income & The household's monthly income before tax deduction (unit: million Korean won) & 4.16 \\
Householder & A dummy for the respondent's being a householder $(0=$ no; $1=$ yes $)$ & 2.00 \\
Education & The respondent's education level in years & 1.46 \\
Gender & The respondent's gender $(0=$ male; $1=$ female $)$ & 13.91 & 0.50 \\
\hline
\end{tabular}

The covariates were reflected in the model by inserting them into $\gamma_{0}$ in Equation (1). Therefore, the positive sign of the coefficient for a variable indicates that the variable has a positive correlation to the probability of reporting "yes" to an offered bid. Table 6 shows the estimation results of the 
model with covariates. The coefficient estimate for the bid amount term was statistically significant. More importantly, the estimated coefficient for the bid amount variable was negative as expected. The coefficient estimates for all variables were statistically meaningful. The respondent's education level was positively related to the probability of reporting "yes" to a given bid. Similarly, richer interviewees were more inclined to accept the payment of a proposed bid than less-rich interviewees. The coefficient estimates for Householder and Gender variables were all negative, meaning that householders had a lower tendency to state "yes" to a proposed bid and male interviewees had a lower probability of saying "yes" to an offered bid than female interviewees.

Table 6. Estimation results of the model with covariates.

\begin{tabular}{|c|c|c|}
\hline Variables $^{a}$ & Coefficient Estimates & $t$-Values \\
\hline Constant & 1.2530 & 1.58 \\
\hline Bid amount ${ }^{b}$ & -0.1200 & $-13.78^{\#}$ \\
\hline Income & 0.8895 & $2.73^{\#}$ \\
\hline Householder & -1.3918 & $-3.81^{\#}$ \\
\hline Education & 0.0847 & $3.17^{\#}$ \\
\hline Gender & -1.4068 & $-3.87^{\#}$ \\
\hline Spike & 0.4848 & $30.57^{\#}$ \\
\hline Yearly mean WTP per household & \multirow{3}{*}{\multicolumn{2}{|c|}{$\begin{array}{l}\text { KRW } 6032 \text { (USD 5.14) } \\
13.46^{\#} \\
\text { KRW } 5251 \text { to } 7036 \text { (USD } 4.48 \text { to } 6.00)\end{array}$}} \\
\hline$t$-value & & \\
\hline $95 \%$ confidence interval $^{c}$ & & \\
\hline Wald statistic ( $p$-value) ${ }^{\mathrm{d}}$ & \multicolumn{2}{|l|}{$181.08(0.000)$} \\
\hline Log-likelihood & \multicolumn{2}{|l|}{-1001.01} \\
\hline Number of observations & \multicolumn{2}{|l|}{1000} \\
\hline
\end{tabular}

\subsection{Discussion of the Results}

It is necessary to expand the findings for the sample to the population level. When the survey was conducted, Korea had 19,523,587 households [33]. However, the number of observations used here was just one thousand. Therefore, the representativeness of our sample should be examined. That is, whether our sample represents the population well or not is the key to obtaining population-level information. This study attempts to look into the issue in two aspects before the expansion is performed. First, random and scientific sampling in gathering the data is quite important to the expansion. As explained above, a professional survey company that has rich experience in field CV surveys commissioned the entire process of the sampling, thereby guaranteeing that the sample maintained a representative nature.

Second, whether some variables for the sample were similar to those for the population or not should be examined. In this regard, the ratio of female respondents, the monthly income of the household, and the size of the household are looked into here. The sample averages for the variables were $50.0 \%$, KRW 4.16 million, and 3.5 persons. The population averages were $50.0 \%$, KRW 4.36 million, and 3.13 persons when the survey was carried out [33]. Interestingly, it seems that there were no significant gaps between the two values for each variable. This finding makes the representativeness of our sample even stronger. Thus, the findings from the sample can be expanded to the inference of the population values.

The way in which the covariates are selected may affect the mean WTP estimate. Thus, the mean WTP estimate found in models with no covariates was used in expanding the sample figure to the population figure instead of that in the model with covariates. When the yearly values concerning the first and the total number of households in Korea are used, we can compute the total WTP, expanded to the relevant population. As shown in Table 7, it was found that the population's WTP for reducing 
the incidence of oil spill accidents in Korean rivers by half was KRW 120.8 billion (USD 103.0 million) per annum. The 95\% confidence interval for the total WTP value was KRW 105.8 to 139.1 billion (USD 90.2 to 118.5 million). It appears that reducing the incidence of oil spill accidents in Korean rivers by half contributes to Korean households' utility.

Table 7. Estimation of total willingness to pay (WTP).

\begin{tabular}{ccc}
\hline & Estimates & $\mathbf{9 5 \%}$ Confidence Intervals \\
\hline Mean annual WTP per household & KRW 6188 & KRW 5418 to 7125 \\
& (USD 5.28) & (USD 4.62 to 6.07) \\
\hline Total annual WTP & KRW 120.8 billion & KRW 105.8 to 139.1 billion \\
& (USD 103.0 million) & (USD 90.2 to 118.5 million) \\
\hline
\end{tabular}

Note: Korea had 19,523,587 households when the survey was carried out.

Oil spill accidents are increasing every year in Korea, and some findings that emerge from our CV survey show that Korean households are concerned about oil spill accident damage. This means that a number of households want to enforce strong and systematic incident response regulations of oil spill accidents in rivers. Therefore, the Korean Government needs to execute a joint public and private response and endeavor actively to reduce the incidence of oil spill accidents in rivers.

\section{Conclusions}

Oil spill accidents in rivers damage a wide range of resources (e.g., human health and the ecosystem), due to the hazardous and toxic substances in the oil. When these substances enter the human body or animals, they cause adverse effects in relation to cancer, fetal growth, cardiovascular disease, bioaccumulation, and so on. To reduce oil spill accidents, it is important to tighten the regulations in the systematic reduction plan. Therefore, the Korean Government is trying to implement a plan to reduce the incidence of oil spill accidents in rivers by half. This article applied a CV technique to assess the public value of the reduction plan. The estimate for the mean annual WTP for the reduction was KRW 6188 (USD 5.28) per household. It has statistical meaningfulness at the $1 \%$ level and the sample also represented the population well. Expanding the value to the whole country resulted in KRW 120.8 billion (USD 103.0 million) per year. In addition, the ratio of yearly mean WTP per household to the household's yearly income was $0.012 \%$.

This article tried to contribute to the current literature by deriving the household WTP for reducing the incidence of oil spill accidents in rivers by half and evaluating the public value of the reduction plan. To the best of the authors' knowledge, there are a few studies that dealt with the issue. Thus, the study provided empirical evidence that the CV approach, which is theoretically grounded in microeconomics, could be successfully utilized in measuring the national public value of the reduction. Although river oil spill accidents are less likely to occur than one caused by marine oil spill, rivers should also be managed systematically because of their use for drinking water and agricultural water. However, there is a lack of specific government management programs such as accident response and prevention systems, as well as relief systems for environmental pollution. Therefore, the authors think that the framework of the study can be extended in future studies in several ways.

It is costly to reduce oil spill accidents in rivers by carrying out the government plan. Since the cost will eventually be covered by the national tax levied on people, it is vital to gather public opinion on whether or not to pay for the reduction. This is because the reduction cannot be successful without public support for the reduction. In particular, policy makers ask for quantitative information about people's WTP for the reduction. The purpose of this study was to provide information to policy makers. In this regard, the results from the study are useful from the perspective of policy.

For example, we need to break down the public value to non-use and use values. Overall, the residents' interest in reducing the oil spill accidents is on the rise, and they reported a significant WTP for the reduction. In the CV survey, some respondents stated that they were not and would 
not be harmed by the oil spill accidents but were willing to pay some amount to reduce the oil spill accidents. Thus, it appears that the WTP reflects not only use value, but also non-use value. In other words, reducing the incidence of oil spill accidents in rivers by half is quite important to the residents, even if some of them do not directly benefit from the reduction. The non-use value reflects altruistic values. Therefore, we found that people were willing to pay a significant amount for the reduction of the oil spill accidents in rivers.

Moreover, we need to examine how the value varies as time passes by conducting the CV survey every year for some years and analyzing the CV data. Investigating how much the value changes across the regions and identifying other geographic factors which affect the value are also a good research topic. Comparing the findings from this study with those from other studies for foreign countries and analyzing the gap between the two enables us to obtain new insight into the WTP estimate. These works can provide us with a new point of view concerning the public value.

Acknowledgments: This work was supported by the Korea Institute of Energy Technology Evaluation and Planning (KETEP) and the Ministry of Trade, Industry \& Energy (MOTIE) of the Republic of Korea (No. 20164030201060).

Author Contributions: All the authors played an important role in the preparation of this paper. Hye-Jeong Lee wrote most of the paper; Hyo-Jin Kim conducted the empirical analysis; and Seung-Hoon Yoo took charge of making the survey questionnaire and gathering the data.

Conflicts of Interest: The authors declare no conflict of interest.

\section{References}

1. Ekaram, Y.D. Ecological impact from chemicals in the Arabian Gulf due to Gulf oil spill. Water Environ. J. 2010, 24, 65-73.

2. Khan, M.A.Q.; Al-Ghais, S.M.; Al-Marri, S. Petroleum hydrocarbons in fish from the Arabian Gulf. Environ. Contam. Toxicol. 1995, 29, 517-522. [CrossRef]

3. Sturve, J.; Balk, L.; Liewenborg, B.; Adolfsson-Erici, M.; Förlin, L.; Almroth, B.C. Effects of an oil spill in a harbor assessed using biomarkers of exposure in eelpout. Environ. Sci. Pollut. Res. 2014, 21, 13758-13768. [CrossRef] [PubMed]

4. Amini, H.; Hosseini, V.; Schondler, C.; Hassankhany, H.; Yunesian, M.; Henderson, S.B.; Künzli, N. Spatiotemporal description of BTEX volatile organic compounds in a Middle Eastern megacity: Tehran study of exposure prediction for environmental health research (Tehran SEPEHR). Environ. Pollut. 2017, 226, 219-229. [CrossRef] [PubMed]

5. Cakmak, S.; Hebbem, C.; Cakmak, J.D.; Dales, R.E. The influence of polycyclic aromatic hydrocarbons on lung function in a representative sample of the Canadian population. Environ. Pollut. 2017, 228, 1-7. [CrossRef] [PubMed]

6. Korea Environment Corporation. Available online: http://www.waterkorea.or.kr (accessed on 20 April 2017). (In Korean)

7. Ministry of Environment. Environmental Disaster Integrated Management Technology Development Project; Ministry of Environment: Kwacheon, Korea, 2013.

8. Celik, M.; Topcu, Y.I. Use of an ANP to prioritize managerial responsibilities of maritime stakeholders in environmental incidents: An oil spill case. Transp. Res. D Transp. Environ. 2009, 14, 502-506. [CrossRef]

9. Ferrando, A.; Gonzalez, E.; Franco, M.; Commendatore, M.; Nievas, M.; Militon, C.; Stora, G.; Gilbert, F.; Esteves, J.L.; Cuny, P. Oil spill effects on macrofaunal communities and bioturbation of pristine marine sediments (Caleta Valdés, Patagonia, Argentina): Experimental evidence of low resistance capacities of benthic systems without history of pollution. Environ. Sci. Pollut. Res. 2015, 22, 15294-15306. [CrossRef] [PubMed]

10. Guidi, G.; Sliskovic, M.; Violante, A.C.; Vukic, L. Best available techniques (BATs) for oil spill response in the Mediterranean Sea: Calm sea and presence of economic activities. Environ. Sci. Pollut. Res. 2016, 23, 1944-1953. [CrossRef] [PubMed] 
11. De Padova, D.; Mossa, M.; Adamo, M.; De Carolis, G.; Pasquariello, G. Synergistic use of an oil drift model and remote sensing observations for oil spill monitoring. Environ. Sci. Pollut. Res. 2017, 24, 5530-5543. [CrossRef] [PubMed]

12. Cai, L.; Yan, L.; Ni, J.; Wang, C. Assessment of Ecological Vulnerability under Oil Spill Stress. Sustainability 2015, 7, 13073-13084. [CrossRef]

13. Luo, M.; Shin, S.H. Half-century research developments in maritime accidents: Future directions. Accid. Anal. Prev. 2016. [CrossRef] [PubMed]

14. Krahn, M.M.; Kittle, L.J., Jr.; MacLeod, W.D., Jr. Evidence for exposure of fish to oil spilled into the Columbia River. Mar. Environ. Res. 1986, 20, 291-298. [CrossRef]

15. Clark, R.M.; Vicory, A.H.; Goodrich, J.A. The Ohio River oil spill: A case study. J. Am. Water Works Assoc. 1990, 82, 39-44. [CrossRef]

16. Cronk, J.K.; Mitsch, W.J.; Sykes, R.M. Effective modelling of a major inland oil spill on the Ohio River. Ecol. Model. 1990, 51, 161-192. [CrossRef]

17. Yapa, P.D.; Shen, H.T. Modelling river oil spills: A review. J. Hydraul. Res. 1994, 32, 765-782. [CrossRef]

18. Giari, L.; Dezfuli, B.S.; Lanzoni, M.; Castaldelli, G. The impact of an oil spill on organs of bream Abramis brama in the Po River. Ecotoxicol. Environ. Saf. 2012, 77, 18-27. [CrossRef] [PubMed]

19. Carson, R.T.; Mitchell, R.C.; Hanemann, W.M.; Kopp, R.J.; Presser, S.; Ruud, P.A. Contingent valuation and lost passive use: Damages from the Exxon Valdez oil spill. Environ. Res. Econ. 2003, 25, 257-286. [CrossRef]

20. Van Biervliet, K.; Le Roy, D.; Nunes, P.A. An Accidental Oil Spill along the Belgian Coast: Results from a CV Study; FEEM Working Paper 41; Fondazione Eni Enrico Mattei: Milano, Italy, 2006.

21. Ahtiainen, H. The Willingness to Pay for Reducing the Harm from Future Oil Spills in the Gulf of Finland-an Application of the Contingent Valuation Method. Discussion Papers. 2007. Available online: http://hdl. handle.net/1975/1479 (accessed on 20 September 2017).

22. Loureiro, M.L.; Loomis, J.B.; Vazquez, M.X. Economic valuation of environmental damages due to prestige oil spill in Spain. Environ. Res. Econ. 2009, 44, 537-553. [CrossRef]

23. Casey, J.F.; Kahn, J.R.; Rivas, A.A.F. Willingness to accept compensation for the environmental risks of oil transport on the Amazon: A choice modeling experiment. Ecol. Econ. 2008, 67, 552-559. [CrossRef]

24. Liu, X.; Wirtz, K.W.; Kannen, A.; Kraft, D. Willingness to pay among households to prevent coastal resources from polluting by oil spills: A pilot survey. Mar. Pollut. Bull. 2009, 58, 1514-1521. [CrossRef] [PubMed]

25. Park, S.Y.; Lim, S.Y.; Yoo, S.H. The economic value of the national meteorological service in the Korean household sector: A contingent valuation study. Sustainability 2016, 8, 834. [CrossRef]

26. Lee, C.H.; Kang, Y.A.; Chang, K.J.; Kim, C.H.; Hur, J.I.; Kim, J.Y.; Lee, J.K. Acute health effects of the Hebei oil spill on the residents of Taean, Korea. J. Prev. Med. Public Health 2010, 43, 166-173. [CrossRef] [PubMed]

27. Hong, S.J.; Kim, J.S.; Ryu, J.S.; Park, J.S.; Song, S.J.; Kwon, B.O.; Choi, K.H.; Ji, K.H.; Seo, J.H.; Lee, S.W.; et al. Two years after the Hebei Spirit oil spill: Residual crude-derived hydrocarbons and potential AhR-mediated activities in coastal sediments. Environ. Sci. Technol. 2012, 46, 1406-1414. [CrossRef] [PubMed]

28. Kim, D.; Yang, G.G.; Min, S.; Koh, C.H. Social and ecological impacts of the Hebei Spirit oil spill on the west coast of Korea: Implications for compensation and recovery. Ocean Coast. Manag. 2014, 102, 533-544. [CrossRef]

29. Kim, T.G.; Opaluch, J.; Moon, D.S.H.; Petrolia, D.R. Natural resource damage assessment for the Hebei Spirit oil spill: An application of Habitat Equivalency Analysis. Mar. Pollut. Bull. 2017, 121, 183-191. [CrossRef] [PubMed]

30. Champ, P.A.; Boyle, K.J.; Brown, T.C.A. Primer on Nonmarket Valuation; Kluwer Academic Publisher: Dordrecht, The Netherlands, 2004.

31. Hanemann, W.M. Welfare evaluations in contingent valuation experiments with discrete responses. Am. J. Agric. Econ. 1984, 66, 332-341. [CrossRef]

32. Kriström, B. Spike models in contingent valuation. Am. J. Agric. Econ. 1997, 79, 1013-1023. [CrossRef]

33. Statistics Korea. Available online: http:/ / kosis.kr (accessed on 20 September 2017).

34. Johnston, R.J.; Boyle, K.J.; Adamowicz, W.; Bennett, J.; Brouwer, R.; Cameron, T.A.; Hanemann, W.M.; Hanley, N.; Ryan, M.; Scarpa, R.; et al. Contemporary guidance for stated preference studies. J. Assoc. Environ. Resour. Econ. 2017, 4, 319-405. [CrossRef] 
35. Hanemann, W.M.; Loomis, J.; Kanninen, B.J. Statistical efficiency of double-bounded dichotomous choice contingent valuation. Am. J. Agric. Econ. 1991, 73, 1255-1263. [CrossRef]

36. Krinsky, I.; Robb, A.L. On approximating the statistical properties of elasticities. Rev. Econ. Stat. 1986, 68, 715-719. [CrossRef]

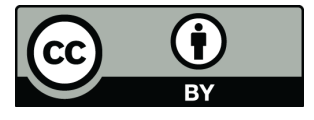

(c) 2018 by the authors. Licensee MDPI, Basel, Switzerland. This article is an open access article distributed under the terms and conditions of the Creative Commons Attribution (CC BY) license (http:/ / creativecommons.org/licenses/by/4.0/). 